\title{
Improved Rigid Cable Method for Prestress Optimization of Suspen-dome Structure
}

\author{
Wenfeng Du*, Shuailiang Zhang, Longxuan Wang and Pengfei He \\ Institute of Steel and Spatial Structure in School Civil Engineering and Architecture, Henan University, Kaifeng 475004 China \\ *Corresponding author
}

\begin{abstract}
For considering the losses of prestress in suspendome structure after pre-stress optimization using rigid cable method, an improved rigid cable method was proposed. The temperature stress is applied to corresponding element to compensate the loss of prestress, and the relationship between temperature and prestess loss is deduced. An example and engineering application are discussed. Results show that the improved rigid cable method is effective and applicable.
\end{abstract}

Keywords-suspen-dome structure; losses of prestress; rigid cable method

\section{INTRODUCTION}

Stringed dome structure is a kind of self-balanced structure system composed of three elements of cable, rod and beam. Through the appropriate prestressing to the cable, the singlelayer lattice shell of the strut generates the opposite displacement when using the load, which will achieve the effect of improving the structural rigidity and reducing the internal force of the grid shell rod, while the lower inclined cable can offset the horizontal thrust at the support. Pestress of cable is an externally-controlled assembly force whose size has a significant effect on the internal force distribution and displacement of the structure. If prestress of cable isn't properly applied, which will be counterproductive. Excessive prestress not only does not play the role of prestress, but also makes the cable exceed its ultimate tensile load under the action of damage, and too low prestress can't meet the structural requirements of the stiffness.

So it is reasonable determining the level of prestress, which is one of the key issues in the design of the suspen-dome structure.

\section{PRestressed Optimization Method}

\section{A. Three Prestressed Optimization Methods}

Prestressed cable is the most active and sensitive element in the suspen-dome structure. The value of prestress in practical engineering must be reasonable, and the value range should be the process of initial state to load state when the structure is formed as a whole. The axial force of the upper monolayer reticulated shell should be reduced as much as possible while taking into account the influence on structural stability and horizontal thrust.

At present, there are three main methods to optimize the cable prestress of the suspen-dome structure. The first is the geometric method. The method uses the vertical upward force generated by the struts at different locations of the cable to be equal to the equivalent node load on the single-layer lattice shell. Based on the inner radial cable and the adjacent outer ring pole in the winding node and static load balance to determine the proportion of prestressed ring method [1]. The second is rigid cable method. This method refers to the method of prestress analysis in cable-stayed bridge, ie, magnifying the elastic modulus of the lower cable by several times, doing static analysis without prestressing, and then confirming each circle according to the calculation result Prestress ratio [2,3]. The third tangential balance method, so that the inner radial cable and the adjacent outer ring bar connected to the winding node in the outer force generated in the upper shell spherical tangential principle to determine the proportion of prestress the ring $[4,5]$. The case analysis and comparison study show that the stress and node displacement of the rod members are all uniform with the rigid cable method. However, the prestress applied by the geometric method and the tangential balance method changes the shape of the reticulated shell $[4,5]$.

\section{B. Improve Rigid Rope Method}

The concept of rigid cable method is clear and easy to operate. However, the rigid cable method applies prestress to the structural unit by applying the initial strain. If the prestress value is directly converted into the initial strain and applied to the corresponding cable, the cable structure will be rebalanced Deformation, leading to loss of cable prestress.

In order to accurately apply the equilibrium prestress, it is necessary to consider the prestress loss of the cable after structural rebalance. First of all, according to the rigid cable method, the section of each lap cable is estimated in advance. The elastic modulus of the cable is increased by 100 times and the initial strain is 0 , and the tension force of each cable unit can be obtained by using the ANSYS software to calculate the tensile force of $\mathrm{Ni}$.

Then the elastic modulus of the cable was changed back to the original value, and the initial strain was calculated according to $\mathrm{Ni}$, which is applied to the corresponding cable element, and the static force calculation was performed again to obtain the pulling force of each cable element at this moment, which is denoted as $\mathbb{N}_{i}$.

There is a loss of prestress between the tension of each cable unit and the tension after rebalancing:

$$
\Delta \mathrm{N}_{\mathrm{i}}=\mathrm{N}_{\mathrm{i}}-\mathrm{N}_{\mathrm{i}}
$$

Next, the prestress for these losses can be compensated for with temperature stress. 


$$
\begin{gathered}
\Delta \mathrm{N}_{\mathrm{i}}=\Delta \sigma \mathrm{A}_{\mathrm{i}} \\
\Delta \sigma \mathrm{A}_{\mathrm{i}}=\Delta \mathrm{L} \mathrm{E}_{\mathrm{i}}^{*} \mathrm{~A}_{\mathrm{i}} / \mathrm{L} \\
\Delta \mathrm{L}=\mathrm{T}_{\mathrm{i}} \alpha_{\mathrm{i}} * \mathrm{~L}
\end{gathered}
$$

Where $\sigma$ is the stress, $\mathrm{A}$ is the cross-sectional area, $\mathrm{L}$ is the length, $\mathrm{E}$ is the modulus of elasticity and $\mathrm{T}$ is the temperature, $\alpha$ is the coefficient of linear thermal expansion of the material at temperature.

$$
\mathrm{T}_{\mathrm{l}}=\Delta \mathrm{N}_{\mathrm{l}} /\left(\mathrm{E}_{\mathrm{l}} * \mathrm{~A}_{1} * \mathrm{a}_{\mathrm{l}}\right)
$$

Therefore, if the temperature $\mathrm{Ti}$ is applied to the corresponding cable unit, the temperature stress can be used to compensate for the loss of the prestress $\Delta \mathrm{Ni}$. At this time, the recalculation of the pulling force of each cable unit is the prestress that the equilibrium state is expected to be applied.

The above analysis method of improving rigid cable method adopts the method of applying temperature stress to make up for the loss of cable internal prestress caused by the deformation of cables after structural rebalance.

\section{Examples}

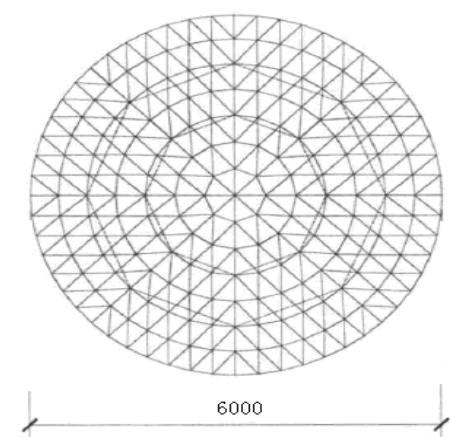

FIGURE I. STRING BRANCH DOME PLANE

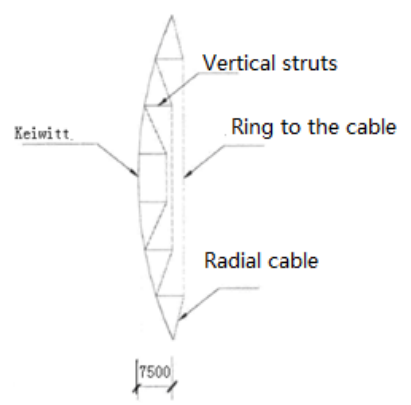

FIGURE II. STRING BRANCH DOME FACADE

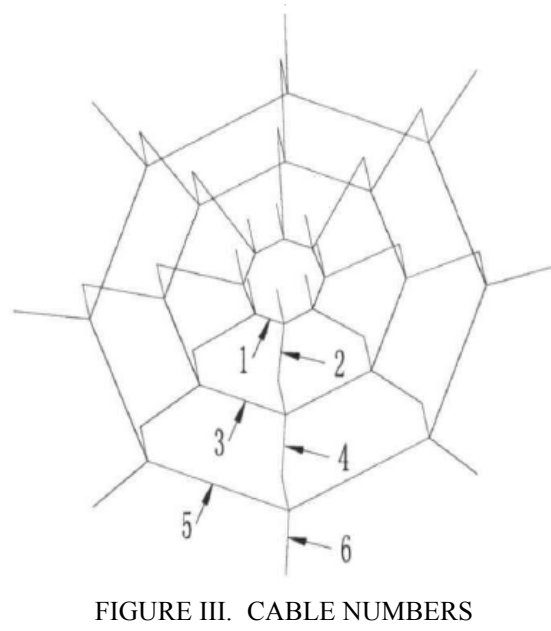

As shown in Figure 1, the chord support dome has a span of $60 \mathrm{~m}$ and a height of $7.5 \mathrm{~m}$. Three rings of ring cables are arranged. The same cross-section of the radial cables and hoop cables of the same ring is used. The innermost cable is PES5$37\left(726 \mathrm{~mm}^{2}\right)$. Ring cable is PES5-55 $\left(1080 \mathrm{~mm}^{2}\right)$. Outer ring cable is PES5-109 $\left(2139 \mathrm{~mm}^{2}\right)$. Tilting the cords along the eight radial ribs, Structure withstand vertical uniform load. Singlelayer reticulated shell members use $\varnothing 180$ round bar and the bar use $\varnothing 159$ round tube. Steel elastic modulus is $2.06 \mathrm{E} 11 \mathrm{~N} / \mathrm{m}^{2}$ and cable elastic modulus is $1.9 \mathrm{E} 11 \mathrm{~N} / \mathrm{m}^{2}$ and steel linear expansion coefficient is $1.2 \mathrm{e}-5$. The peak load is $14.1 \mathrm{kN}$ and the load of the outermost node is $5.7 \mathrm{kN}$ and the load of the other nodes is $11.55 \mathrm{kN}$. The three lap ring cable, radial cable were numbered as 1, 2, 3, 4, 5, 6 group cable, shown in Figure 2. When using ANSYS for calculation, the winding rod adopts the BEAM4, and the nodes are just connected. Rod adopts LINK8 and cable adopts LINK10, and prestress is applied by applying the initial strain method.

Table 1 shows the structure of the example using the rigid cable method and the improved rigid cable method. Table 1 shows that the use of rigid cable method, the recalculated loss of prestress about $13 \%$, which is not to be ignored. With the improved rigid cable method, the cooling compensation of each corresponding cable unit needs to be compensated. The error between recalculated prestress and expected prestress is up to about $1 \%$. One reason for this error is that the choice of the decimal places in the calculation process is caused by the other reason that the structure has certain geometric nonlinearity. 
TABLE I. PRESTRESSED OPTIMAL DESIGN VALUE (KN)

\begin{tabular}{|l|l|l|l|l|l|l|}
\hline Cable number & 1 & 2 & 3 & 4 & 5 & 6 \\
\hline $\begin{array}{l}\text { Rigid cable } \\
\text { method(KN) }\end{array}$ & 41.760 & 36.296 & 196.499 & 162.702 & 700.00 & 558.016 \\
\hline recalculate(KN) & 36.179 & 31.422 & 170.676 & 141.355 & 611.314 & 487.477 \\
\hline Prestress loss(KN) & 5.581 & 4.874 & 25.823 & 21.347 & 88.686 & 70.539 \\
\hline $\begin{array}{l}\text { Prestress loss } \\
\text { percentage }\end{array}$ & 13.364 & 13.428 & 13.142 & 13.120 & 12.669 & 12.641 \\
\hline $\begin{array}{l}\text { Apply } \\
\left.\text { temperature( }{ }^{\circ} \mathrm{C}\right)\end{array}$ & -3.372 & -2.945 & -10.4879 & -8.669 & -18.185 & -14.464 \\
\hline $\begin{array}{l}\text { Recalculate } \\
\text { again(KN) }\end{array}$ & 41.420 & 35.886 & 194.628 & 160.934 & 697.057 & 555.053 \\
\hline \begin{tabular}{l} 
error \\
\hline
\end{tabular} & 0.814 & 1.130 & 0.952 & 1.087 & 0.420 & 0.531 \\
\hline
\end{tabular}

\section{OPtIMUM EXAMPLE OF PRESTRESSING OF SLANTING DOME IN QINYANG GYMNASIUM}

The roof adopts the chord dome structure, which is supported by 32 hinge supports on the concrete ring beam. Winding for the Kaweite form single-layer spherical reticular shell, the outermost edge of the ring is sunflower arrangement, the lower part of the arrangement of 4 rings, strut height from the inside to outside $4.5 \mathrm{~m}, 5 \mathrm{~m}, 5.5 \mathrm{~m}, 6.0 \mathrm{~m}$. Single-layer reticulated shell members are used Q345B steel section, which is a total of $7 \mathrm{kinds}$ of rod. The smallest is $\varnothing 219 \times 6$ and the largest is $\varnothing 500 \times 25$ and the strut is $\varnothing 245 \times 8$. Ring to the cable from the inside to the outside using high strength steel wire bundle (tensile strength $1670 \mathrm{MPa}$ ), section is $\varnothing 7 \times 55$, $\varnothing 7 \times 55$, $\varnothing 7 \times 109, \varnothing 7 \times 109$. The outermost ring of radial cable is made of high strength steel rod with $\varnothing 60 \mathrm{~mm}$ diameter (yield strength $550 \mathrm{MPa})$. The second outer ring is made of high strength steel rod with $\varnothing 50 \mathrm{~mm}$ diameter. The other inner rings are made of high strength steel rod with diameter of $\varnothing 50 \mathrm{~mm}$. The elastic modulus of the steel pipe is $2.06 \times \mathrm{E} 11 \mathrm{~N} / \mathrm{m}^{2}$ and the elastic modulus of the cable is $1.9 \times \mathrm{E} 11 \mathrm{~N} / \mathrm{m}^{2}$. The initial tension of the hoop cable is introduced through the initial strain of the application unit. The prestressing force controlled by the prestressing force of the hoop cable from the inside to the outside is obtained through the prestress optimization design. The initial pulling force of the radial cable is indirectly introduced through the hoop cable. Reticulated node is just connected, the connecting point between strut and reticulated shell and the connecting point between strut and cable are hinged. Roof single-layer reticulated shell and cable system as shown in Figure 4 and Figure 5.

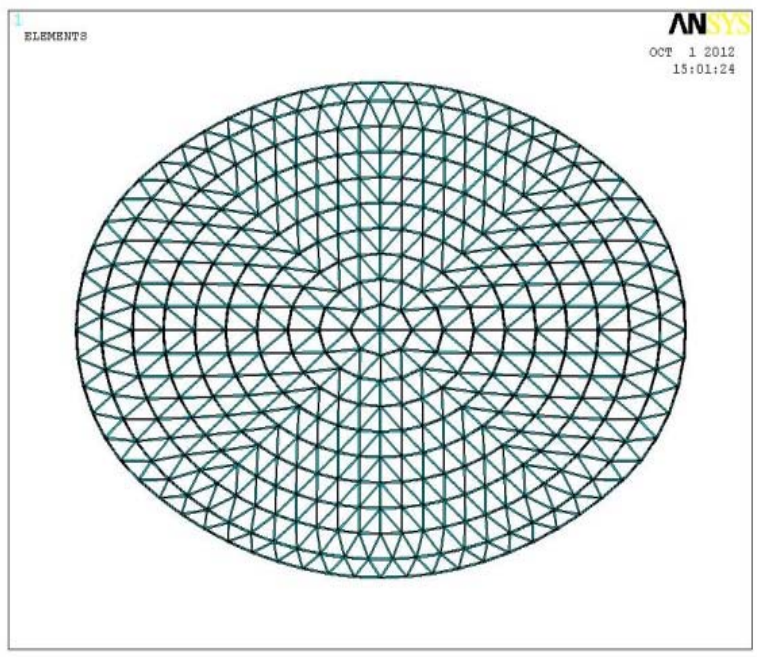

FIGURE IV. ROOF SINGLE-LAYER RETICULATED SHELL

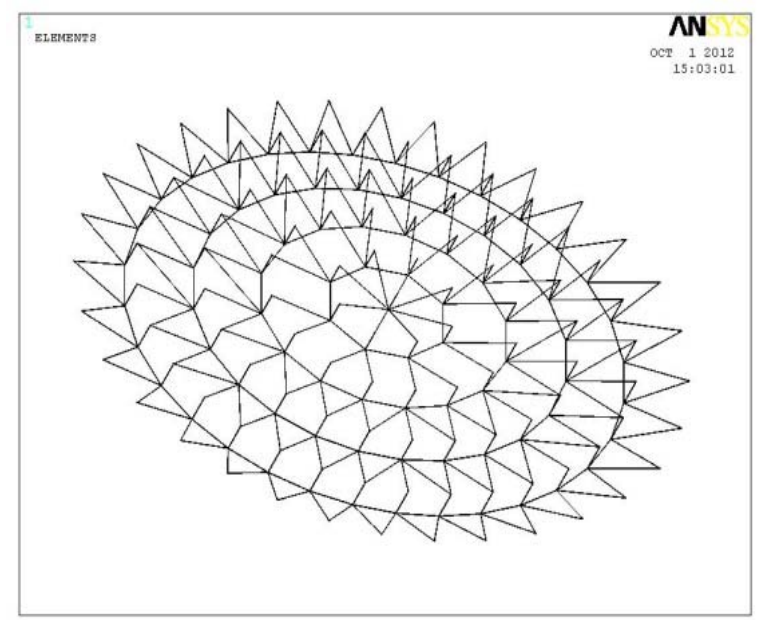

FIGURE V. ROOF CABLE SYSTEM 
Table 2 shows the structure of the improved rigid method of calculation results. It can be seen that with the rigid cable method, the recalculated prestress loss is about $30 \%$. However, with the improved rigid cable method, the cooling compensation for each cable unit needs to be compensated. The error between the recalculated prestress and the expected prestress is the largest Less than $5 \%$.P
At the same time, the calculation results show that the maximum vertical displacement of the structure is $46.1 \mathrm{~mm}$, the maximum axial pressure of the top single-layer shell member is $596 \mathrm{kN}$, the average radial displacement of the support joint is $0.7 \mathrm{~mm}$, and the optimization result of the cable prestress is ideal.

TABLE II. PRESTRESSED OPTIMAL DESIGN VALUE (KN)

\begin{tabular}{|l|l|l|l|l|}
\hline Ring cable location & The innermost ring & The inner ring & Outer ring & The outermost ring \\
\hline Rigid cable method(KN) & 37.64 & 482.71 & 1677.96 & 2887.5 \\
\hline recalculate(KN) & 23.56 & 356.38 & 1129.96 & 1947.9 \\
\hline Prestress loss percentage & 37.4 & 26.2 & 32.6 & 32.5 \\
\hline Apply temperature(oC) & -2.92 & -26.19 & -57.3 & -98.3 \\
\hline Recalculate again(KN) & 35.84 & 475.22 & 1624.89 & 2736.81 \\
\hline error & 4.78 & 1.55 & 3.16 & 5.22 \\
\hline
\end{tabular}

\section{SUMMARY}

(1) Of the three methods for cable prestress optimization of the suspen-dome structure, the rigid cable method is the most convenient and the stress and node displacement of the winding rod are relatively uniform. However, the defect is caused by applying the initial strain to the structural unit prestressing is applied. If the prestress value is directly converted into the initial strain and applied to the corresponding cable, the cable will be deformed after the structure is rebalanced, resulting in loss of prestressing force in the cable.

(2) It is a good attempt to make up for the loss of cable prestress caused by the deformation of the cable after the structure rebalance due to the application of thermal stress. The results of the calculation and the actual engineering proves the effectiveness of this method.

\section{REFERENCES}

[1] Zhang Ming-Shan, Zhang Shi-Hong.Determination and Stability Analysis of Initial Prestressing Distribution of Slab Dome [J]. Spatial Structure, 2004, 10 (2): 8-12.

[2] Zhang Xiaofeng. Research on overall stability and dynamic performance of suspend dome in Olympic badminton stadium [D] .Beijing: Beijing University of Technology, 2008.

[3] Wang Bohui. Cable-stayed bridge structure development and China's experience. Transportation Press, 2004.

[4] Fu Zhiqiang. Dynamic catastrophic dome structure of the disaster [D]. Hangzhou: Zhejiang University master's degree thesis, 2008.

[5] Yang Bo, Dai Guoxin, Nie Shidong, and so on. ZHAO Jin-hua.Preoptimization of Chamfered Triangular Dome Structures [J]. Construction Technology, 2010, 40 (5): 100-104. 